\title{
NOTES
}

\section{CORRECTIONS AND SUBSTANTIATIONS TO KBNK}

\author{
H. Zellner, H.J. van den Herik, I.S. Herschberg
}

The senior author, by letter of July 26,1987 , suggested that the junior authors' results, as published in the ICCA Journal, Vol.8, No.2, pp. 66-87, cannot possibly be right, since the full-board numbers of positions, summed over all moves to mate did not add up to $10,822,184$, as they should, but only to $10,821,420$. The culprits tender their apologies to readers and state that two errors have crept in. The rows as given for 12 and 26 moves-to-mate contain two familiar errors of typography, corrected below.

\begin{tabular}{|c|c|c|}
\hline $\begin{array}{c}\text { number of moves } \\
\text { to mate }\end{array}$ & $\mathrm{B}$ (printed as) & $\mathrm{B}$ (should be) \\
\hline 12 & 142,048 & 142,084 \\
26 & 949,080 & 949,808 \\
\hline
\end{tabular}

These new values of B bring up the sum over B to the proper total, 10,822,184.

The senior author also independently implemented, by mid-September, on an Atari ST, the KBNK database, exactly reproducing the numbers and all but one of the optimal moves. The single discrepancy remaining is that the senior author, at move 26 in Van den Herik and Herschberg $(185, \mathrm{p} .84)$ found 26 . Kd7 $(K d 8) \mathrm{Bb8}$, i.e. two equi-optimal moves for White whereas the junior authors' article gave a single optimal continuation.

Van den Herik and Herschberg gladly concede Kd8 to be equi-optimal. They do not yet, however, have traced the discrepancy to its source, which again might be typographical.

We hope readers will forgive any inconvenience caused. The cure for these ills would appear to be a database-consulting program directly coupled to a lay-out program for its results, an effort still beyond us but not, we hope, for long.

\section{REFERENCE}

Herik, H.J. van den and Herschberg, I.S. (1985). The Construction of an Omniscient Endgame Data Base. ICCA Journal, Vol. 8, No. 2, pp. 66-87.

\section{CHALLENGING THAT MOBILITY IS FUNDAMENTAL}

\author{
Jan Eric Larsson \\ Department of Automatic Control \\ Lund Institute of Technology \\ Sweden
}

The notion of mobility has long been considered to be of fundamental importance in positional evaluation. Several different definitions of mobility exist, and they all show a high correlation with having a good position and eventually winning the game, as shown by experiments. However, this article contests the fundamental importance of mobility. Some alternative, and proposedly more useful, definitions of mobility are given. It is also argued that an extensive, second-order mobility analysis is not cost-effective. 